\title{
Pharmacological Treatment Of Osteoarthritis In A Nutshell
}

\author{
Mehtab Munir, Khalid Mustafa Memon, M Sajid Abbas Jaffri
}

\begin{abstract}
- - - - - - - - - - - - - - - - - - - - - - - - -
ABSTRACT:

Osteoarthritis, an inflammatory, degenerative disease of joints mostly affects weight bearing joints in old age. Treatment modalities are categorized into non-pharmacological, pharmacological and surgical. Among pharmacological options, oral formulations are mostly used. Acetaminophen is considered as first line though, NSAIDs are well established choice for the management of osteoarthritis and mostly employed for the same. However NSAIDs are associated with gastric adverse effects. Symptomatic slow acting osteoarthritis drugs like glucosamine, chondroitin sulfate, diacerein and avocado soybean saponifiables are considered as maintenance therapy as they have shown to reserve joint space width. Topical formulations are good for patients with co-morbidities. For patient not responding to other modalities, opioids and duloxetine are employed but with caution. Intra-articular injections like corticosteroids, hyaluronic acid and Platelet rich plasma are ranked highest in efficacy. Newer agents like Nerve growth factor- $\boldsymbol{\alpha}$ inhibitors, Interleukin-1 antagonists and certain neutraceutical preparations are under investigation for osteoarthritis management.
\end{abstract}

Key words: osteoarthritis, treatment, pharmacological modalities, conservative

$------------------$

\section{INTRODUCTION:}

Osteoarthritis (OA) is an inflammatory and degenerative disease of joints in which mostly weight bearing and hand joints are affected ${ }^{1}$. In OA there is damage of articular cartilage that causes bones to rub against each other leading to pain and loss of movement ${ }^{2}$. It is the most common arthritis and one of the leading causes of disability in world ${ }^{3}$. Commonly affected age is above 50 years and gender is female ${ }^{4}$. According to WHO, worldwide $9.61 \%$ of males and $18.0 \%$ of females over 60 years of age have symptomatic osteoarthritis 5 . India showed the prevalence to be $5.8 \%$ and mostly people over 65 years of age were affected. Prevalence of OA in Northern areas of Pakistan was found to be $3.7 \%$ and there was predominance of knee joint involvement that is $95 \%{ }^{6}$. Because of increasing life expectancy and obesity, prevalence of OA is expected to increase steeply worldwide in next few years ${ }^{7}$.

OA is classified into primary OA, with unknown etiology and secondary OA, having a known etiology. Predictors of $\mathrm{OA}$ are: mechanical injury, age, gender, obesity, genetics, metabolic disorders etc. Pathology of osteoarthritis begins with loss of articular cartilage then spreading to subchondrial bone. The bone shows sclerotic changes, formation of osteophytes and synovitis. Loss of cartilage, synovitis along

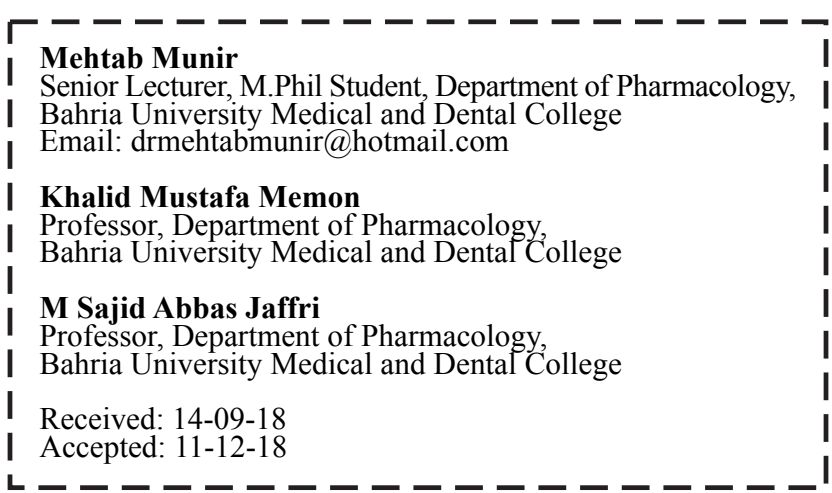

with some other causes, leads to pain ${ }^{8}$.

Common complaints of OA patient are pain and stiffness after long period of movement (exercise) ${ }^{9}$. There can be tenderness, swelling, crepitus and decrease in range of movement on examination. X-ray shows decrease in joint space and osteophytes ${ }^{10}$. Joint space width (JSW), measured on x-ray is considered gold standard for detection of loss of articular cartilage ${ }^{11}$. OA can be graded on plain radiograph according to Kallgren Lawrence grading system ${ }^{12}$. Diagnosis is done using American College of Rheumatology criteria for knee, ${ }^{13}$ hip $^{14}$ and hand joints ${ }^{15}$.

Treatment of OA is non-pharmacological, pharmacological modalities and surgical intervention. (table 1) Long term monitoring course of the disease, follow up and review is also essential $^{16,17}$. Non-pharmacological and pharmacological approaches are conservative management modalities. Pharmacological modalities are the mainstay and commonly employed for the management of osteoarthritis. However succinct information regarding this subject has been found to be lacking. This review is a meek effort to provide current

\begin{tabular}{|c|l|}
\hline Type of treatment & \multicolumn{1}{|c|}{ Examples } \\
\hline $\begin{array}{c}\text { Conservative } \\
\text { A. Non-pharmacological }\end{array}$ & $\begin{array}{l}\text { Exercise, weight loss, physical } \\
\text { therapy, walking cane, shock } \\
\text { absorbing foot wear, acupuncture } \\
\text { etc }\end{array}$ \\
B. Pharmacological & $\begin{array}{l}\text { Oral } \\
\text { Acetaminophen, oral and topical } \\
\text { NSAIDs, SYSOADs, opoids, } \\
\text { duloxetine } \\
\text { Topical } \\
\text { NSAIDs, capsaicin etc } \\
\text { Intra-articular injection } \\
\text { Corticosteroids, hyaluronic acid } \\
\text { etc }\end{array}$ \\
\hline Surgical & $\begin{array}{l}\text { Microfracture, arthroscopy, } \\
\text { arthroplasty etc }\end{array}$ \\
\hline
\end{tabular}

Table 1. Treatment modalities for osteoarthritis 
and approved pharmacological treatment of osteoarthritis.

\section{METHODOLOGY:}

Literature search was done using electronic data bases 'Google scholar' and 'Pubmed' from 2008-2018. Key words and phrases used were osteoarthritis, alone and with treatment, pharmacological treatment, acetaminophen, NSAIDs, diacerein, capsiacin, corticosteroids, hyaluronic acid, duloxetine, platelet rich plasma. Initially 150 articles were selected. Inclusion criteria were original and review articles. Exclusion criteria were animal studies, non-pharmacological and surgical interventions in OA. 60 articles meeting inclusion criteria were included to write this review.

\section{LITERATURE REVIEW:}

Pain is the main and early symptom of OA and other types of arthritis. The core ingredient for management of pain is the pharmacological treatment. ${ }^{18}$ This includes primarily oral, topical and intra-articular formulations.

\section{a. Oral}

i) Acetaminophen

Acetaminophen is recommended as first line treatment of $\mathrm{OA}$ and is well tolerated. It is a non-prescription drug and suitable for OA of mild to moderate severity. Acetaminophen is a non-opioid with anti-pyretic and analgesic properties. Acetaminophen has not proven to be very effective for OA pain in many studies ${ }^{19,20}$, but it has lesser gastric adverse effects as compared to NSAIDs. However patient should be counseled about maximum dose (that is $4 \mathrm{~g}$ ) that can be used per day and concomitant use of any other over-the- counter drugs containing Acetaminophen, as over dosage can cause hepatic toxicity ${ }^{21}$. Recently investigated extended release (ER) Acetaminophen has proven to provide more effective pain relief in $\mathrm{OA}^{22}$.

ii) NSAIDs

Non steroidal anti-inflammatory drugs are well established treatment option for $\mathrm{OA}^{23,24}$. These are inhibitors of cyclooxygenase (COX) enzyme thus halting conversion of arachidonic acid to prostaglandins responsible for inflammation and pain. They are classified as non-selective (inhibiting both $\mathrm{COX} 1$ and 2) and COX-2 selective NSAIDs $^{25}$. Nonselective NSAIDs like Diclofenac, Ibuprofen, Naproxen are significantly associated with gastric adverse effect (because of COX-1 inhibition), hence a proton pump inhibitor is recommended with their use ${ }^{26,27}$. COX-2 selective inhibitors like Celeoxib, Etoricoxib etc have lesser gastrointestinal effects but more prone to cardiovascular events (myocardial infarction, stroke etc) ${ }^{28}$. Based on these facts systemic NSAIDs should be used cautiously especially in elderly OA with co-morbidities or where long term use is required.

iii) Symptomatic Slow acting Drugs for Osteoarthritis (SYSADOA)
SYSADOA include Glucosamine, Chondroitin sulfate, Diacerein and Avocado-Soybean Unsaponifiables (ASU). ${ }^{29}$ Glucosamine and chondroitin sulfate are naturally occurring compounds in body and are substrates for proteoglycan. ${ }^{30}$ Chondroitin sulfate and glucosamine are available in pharmaceutical grade and neutraceutical preparations; however there is striking difference among the two preparations. As pharmaceutical grade preparations are prepared under high quality checks they have shown to be more effective to improve pain and function in $\mathrm{OA}^{31}$. Chondroitin sulfate and glucosamine are recommended to be used as maintenance therapy alone or in combination. Moreover use of this combination for 2 years has shown to reduce joint space $\operatorname{loss}^{32}$.

Diacerein is an anthraquinone derivative, and its active metabolite is rhein. The key mechanism of action of Diacerein is to inhibit the interleukin-1 $\boldsymbol{\alpha}$ (IL-1 $\boldsymbol{\alpha}$ ) system and subsequent signaling. IL-1 $\boldsymbol{\alpha}$ has been found to be increased in synovial fluid of joint affected, hence its inhibition benefits in improving signs and symptoms of $\mathrm{OA}^{33}$. Diacerein can cause stomach upset (dose related), mild skin reactions and rarely hepato-biliary problems but these are much less than adverse effects of NSAIDs ${ }^{34}$. European Society for Clinical and Economic Aspects of Osteoarthritis (ESCEO) recommends Diacerein for patients of OA for whom NSAIDs are not suitable ${ }^{35}$.

ASU are unsaponifiable fraction of avocado and soybean oils. Its anti-OA properties are attributed to many mechanisms like inhibition of interleukin-1 (IL-1), IL-6, IL-8 and TNF$\boldsymbol{\alpha}$. It has also chondro-protective role by stimulating collagen synthesis ${ }^{36}$. Hence it has shown to inhibit deterioration in joint space width (JSW) and demonstrated efficacy in relieving symptoms of knee and hip OA. Moreover safety profile of ASU is good ${ }^{37}$.

iv) Opioid analgesics and duloxetine

Opioid are potent analgesics that act through spinal and supra-spinal opioid $(\mu)$ receptors and provide physical as well as psychological part of pain. These should be prescribed with cautious and weak opioids should be prescribed first, as there is risk of sedation, respiratory depression, misuse, overdose and dependency. Moreover opioids are to be prescribed for short duration of time ${ }^{38}$.

Duloxetine is an anti-depressant drug and is approved by FDA as analgesic for arthritis ${ }^{39}$. It is a potent serotonin and nor-epinephrine reuptake inhibitor (SNRI). These neurotransmitters also play role in central pain pathways. Hence role of Duloxetine is implicated in chronic pain conditions like $\mathrm{OA}^{40}$. Opioids and Duloxetine are treatment options for OA patients who are unresponsive to other pharmacological treatment options, unwilling to undergo surgery or if total arthroplasty is contraindicated, due to higher risk of serious adverse effects ${ }^{1,41}$. 


\section{b. Topical}

i) NSAIDs

Topical NSAIDs are used as alternate to oral formulation. They reduce systemic exposure to NSAIDs, hence beneficial for patients having OA with co-morbidities or elderly. Its mechanism has been discussed above, however considered as safer option than oral NSAIDs as there are no related serious adverse effects ${ }^{42}$. Topical application of ibuprofen, diclofenac, ketoprofen, peroxicam etc are available ${ }^{43}$.

ii) Capsaicin

It is active ingredient of chilies. It provides warmth and desensitizes the nerve endings by inhibiting a pain neurotransmitter, Substance P. There is abundance of nociceptive innervations in joint cartilage and capsaicin is also known to cause selective and reversible destruction of primary afferent fibers. Burning sensation and local skin irritation are main adverse effects ${ }^{44}$. Its use in OA has been recommended by OARSI 2014 and ACR 2012 ${ }^{16,41}$.

\section{c) Intra-articular}

i) Corticosteroids

Intra-articular corticosteroid injections are proven to be quite effective but are reserved for patients not responding to other pharmacological options ${ }^{41}$. Steroids have antiinflammatory and anti-nociceptive actions ${ }^{45}$. Crystalline triamcinolone and non-crystalline prednisolone, methylprednisolone are frequently used ${ }^{46}$. These injections are not recommended more than 3-4 times in a year. Patient's response for pain relief and functional improvement may vary with intra-articular steroids ${ }^{47}$. The effect last for 3 weeks to no more than 6 months ${ }^{46}$.

ii) Hyaluronic acid (HA)

Intra-articular injection of hyaluronic acid and its derivatives is called viscosupplementation. This injection has been approved by FDA, only for knee OA. It is naturally present in synovial fluid, proposed underlying mechanism to reduce pain is restoration of viscoelastic properties of the synovial fluid and reductions in friction within the joint ${ }^{48}$. The evidence for efficacy of this treatment option is controversial. Local adverse reactions are main risk of the injection ${ }^{49}$.

Combination of corticosteroid and hyaluronic acid intraaricular injection has been shown more effective as compared to monotherapy ${ }^{50}$.

iii) Platelet rich plasma (PRP)

PRP is an autologous blood product that is obtained when whole blood is centrifuged to obtain a specific concentration of platelets. The use of PRP is thought to provide cellular and humoral mediators (growth factors) including vascular endothelial growth factor, Fibroblast growth factor b, epidermal growth factor, ?broblast growth factor and plateletderived growth factor for tissue healing especially cartilage repair $^{51}$. PRP has shown to be superior or equally effective as HA in treating knee OA. Moreover PRP has not been found to produce serious local or systemic adverse effects ${ }^{52}$.

Among all the conservative treatment options intra-articular injections are ranked highest in efficacy for management of OA by most of authors and researchers ${ }^{53}$.

\section{d) Others}

Despite the fact here is a long list of drugs for management of OA, an increasing trend has been observed in patients for the use of alternate medicines for few decades ${ }^{46,54}$. This is because of long term use of the drugs for chronic and debilitating disease like osteoarthritis and troublesome adverse effects caused by them. The alternate medicines include herbs like Boswella serrata, curcuminoids, passion fruit peel extract, ginger, rosehip ${ }^{55}$ and dietary supplements like methylsulfonylmethane ${ }^{56}$, vitamin D and K. Although these herbal and neutraceutical products are being used for management of OA, evidence for their efficacy is weak. Hence more studies are warranted in this regard.

\section{e) Drugs under investigation}

Tanezumab is a monoclonal antibody against â-nerve growth factor $\boldsymbol{\alpha}-(\mathrm{NGF}-\boldsymbol{\alpha})$. NGF is involved in causing chronic pain in OA, hence by inhibiting NGF- $\boldsymbol{\alpha}$, Tanezumab is effective for improving symptoms of OA this drug is still under trial but is facing safety issues ${ }^{57}$.

IL-1 receptor antagonists: Anakinra and Orthokin have shown to decrease pain in OA. IL-1 had been shown to increase in synovial fluid of affected joint ${ }^{58}$. Moreover IL$1 \boldsymbol{\alpha}$ antibody Gevokizumab is in phase 11 trials for efficacy and safety in treating hand $\mathrm{OA}^{59}$.

Now focus of research in $\mathrm{OA}$ is on disease modifying agents rather than drugs providing only symptomatic relief. Strontium ranelate $(\mathrm{SrRa})$, presently indicated for prevention of fracture in severe osteoporosis, has shown promising results in reducing cartilage volume loss in OA. It is an element similar to calcium, and is incorporated in bones in place of calcium. SrRa has been proved well tolerated and safe so far ${ }^{60}$.

Intra-articular injection of DNA to modify chondrocytes to produce TNF- $\boldsymbol{\alpha} 1$ and intra-articular injection adipose derived stem cell (ADSC) are also under investigation ${ }^{36}$.

\section{CONCLUSION:}

When pain and function of joint does not respond to nonpharmacological management, pharmacological treatment should be considered. Different pharmacological treatment options are present for management of OA, but treatment should be chosen in stepwise manner, keeping in consideration, individualized needs and benefit-to-risk assessment.

\section{REFERENCES:}

1. Bobacz K. Pharmacologic treatment of hand-, knee- and hiposteoarthritis. Wien Med Wochenschr. 2013; 163:236-42. 
2. Mobasheri A, Bay-jensen A, Spil WE Van, Larkin J, Levesque MC. Osteoarthritis Year in Review 2016?: biomarkers ( biochemical markers ). Osteoarth Cartil. 2017; 25:199-208.

3. BijlsmaJW, BerenbaumF, LafeberFP. Osteoarthritis:an update with relevance for clinical practice. The Lancet. 2011; 377:2115-26.

4. Birtwhistle R, Morkem R, Peat G, Williamson T, Green ME, Khan $\mathrm{S}$ et al. Prevalence and management of osteoarthritis in primary care: an epidemiologic cohort study from the Canadian Primary Care Sentinel Surveillance Network. CMAJ. 2015; 3(3): E270-5.

5. WHO / chronic rheumatic conditions, http://www.who. int/chp/topics/rheumatic/en/ (accessed on 15-07-2018)

6. Akhter E, Bilal S, Haque U. Prevalence of arthritis in India and Pakistan: A review. Rheumatol Int. 2011;31(7):849-55.

7. Zweers MC, Boer TN De, Roon J Van, Bijlsma JWJ, Lafeber FPJG, Mastbergen SC. Celecoxib?: considerations regarding its potential disease-modifying properties in osteoarthritis. Arthritis Res Ther. 2011;13(5): 239-50

8. Vincent TL, Watt FE. Osteoarthritis. Medicine 2014;42 (4),213-9.

9. Cross M, Smith E, Hoy D, Nolte S, Ackerman I, Fransen M, et al. The global burden of hip and knee osteoarthritis: Estimates from the Global Burden of Disease 2010 study. Ann Rheum Dis. 2014;73(7):1323-30.

10. Zhang Y, Jordan JM. Epidemiology of Osteoarthritis. Clin Geriatr Med.2010; 26(3):355-69.

11. Braun HJ, Gold GE. Diagnosis of osteoarthritis: imaging. Bone. 2012;51(2):278-88.

12. Kellgren JH, Lawrence JS. Radiological assessment of osteoarthritis. Ann rheum Dis. 1956; 16(3):494-503.

13. Altman R, Asch E, Bloch D, Bole G, Borenstein D, Brandt $\mathrm{K}$ et al. Development of criteria for the classification and reporting of osteoarthritis. Classification of osteoarthritis of the knee. Diagnostic and Therapeutic Criteria Committee of the American Rheumatism Association. Arthritis Rheum 1986; 29: $1039-49$.

14. Altman R, Alarcon G, Appelrouth D, Bloch D, Borenstein D, Brandt K, et al. The American College of Rheumatology criteria for the classification and reporting of osteoarthritis of the hip. Arthritis Rheum . 1991;34:505-14.

15. Altman R., Alarcon G., Appelrouth D., Bloch D., Borenstein D., Brandt K, et al. The American College of Rheumatology criteria for the classification and reporting of osteoarthritis of the hand. Arthritis Rheum, 1990;33(11),1601-10.

16. NICE. Osteoarthritis: care and management Clinical guideline. 2014;(February 2014). nice.org.uk/guidance/cg177

17. McAlindon TE, Bannuru RR, Sullivan MC, Arden NK, Berenbaum F, Bierma-Zeinstra SM, et al. OARSI guidelines for the non-surgical management of knee osteoarthritis. Osteoarthr Cartil. 2014;22(3):363-88

18. Geenen R, Overman CL, Christensen R, Åsenlöf P, Capela $\mathrm{S}$, Huisinga KL, et al. EULAR recommendations for the health professional's approach to pain management in inflammatory arthritis and osteoarthritis. Ann Rheum Dis. 2018;77 (6):797-807.

19. Machado GC, Maher CG, Ferreira PH, Pinheiro MB, Lin CWC, Day RO et al. Efficacy and safety of paracetamol for spinal pain and osteoarthritis: systematic review and meta- analysis of randomised placebo controlled trials. BMJ. 2015; 350:h1225

20. Stewart M, Cibere J, Sayre EC, Kopec JA. Efficacy of commonly prescribed analgesics in the management of osteoarthritis: a systematic review and meta-analysis. Rheumatol Int. 2018; doi: 10.1007/s00296-018-4132-z.

21. Craig DGN, Bates CM, Davidson JS, Martin KG, Hayes PC, Simpson KJ Staggered overdose pattern and delay to hospital presentation are associated with adverse outcomes following paracetamol-induced hepatotoxicity: outcomes following staggered and delayed paracetamol overdose. Br J Clin Pharmacol. 2012;73(2): 285-94

22. Prior MJ, Harrison DD. 12 week trial of acetaminophen extended release for the treatment of signs and symptoms of osteoarthritis. Curr Med Res Opin. 2014;30(11):2377-87.

23. Robert J. Holt, John G. Fort, Amy Y. Grahn, Jeffrey D. Kent \& Alfonso E. Bello Onset and durability of pain relief in knee osteoarthritis: Pooled results from two placebo trials of naproxen/esomeprazole combination and celecoxib. Physi Sportsmed. 2015;43(3) 200-12.

24. Costa BR, Reichenbach S, Keller N, Nartey L, Wandel S, Jüni P, et al. Effectiveness of non-steroidal anti-inflammatory drugs for the treatment of pain in knee and hip osteoarthritis?: a network meta-analysis. The Lancet. 2017; 387(10033) 2093-105.

25. Song GG, Seo YH, Kim J-H, Choi SJ, Ji JD, Lee YH. Relative efficacy and tolerability of etoricoxib, celecoxib, and naproxen in the treatment of osteoarthritis. Z Rheumatol. 2016;75(5): 508-16.

26. Massó González EL, Patrignani P, Tacconelli S, García Rodríguez LA. Variability among nonsteroidal antiinflammatory drugs in risk of upper gastrointestinal bleeding. Arthritis Rheum. 2010;62(6):1592-601.

27. Lanza FL, Chan FK, Quigley EMM. Guidelines for prevention of NSAID-related ulcer complications. Am J Gastroenterol 2009;104(3):728-38.

28. Coxib and traditional NSAID Trialists' (CNT) Collaboration. Bhala N, Emberson J, Merhi A, Abramson S, Arber N, et al. Vascular and upper GI effects of non-steroidal antiinflammatory drugs: meta-analyses of individual participant data from randomized trials. The Lancet 2013;382(9894): 769-79

29. Kongtharvonskul J, Anothaisintawee T, McEvoy M, Attia J, Woratanarat P, Thakkinstian A. Efficacy and safety of glucosamine, diacerein, and NSAIDs in osteoarthritis knee: A systematic review and network meta-analysis. Eur J Med Res. 2015;20(1):1-11

30. Zhu X, Sang L, Wu D, Rong J, Jiang L. Effectiveness and safety of glucosamine and chondroitin for the treatment of osteoarthritis?: a meta-analysis of randomized controlled trials. J Orthop Surg Med.2018;13(1);170.

31. Fransen M, Agaliotis M, Nairn L, Votrubec M, Bridgett L, $\mathrm{Su}$ S,et al. Glucosamine and chondroitin for knee osteoarthritis: a double-blind randomised placebo-controlled clinical trial evaluating single and combination regimens. Ann Rheum Dis 2015;74(5):851-8 .

32. Lane NE, Shidara K, Wise BL. Osteoarthritis year in review 2016?: clinical. Osteoarthr Cartil. 2017;25(2):209-15.

33. Brandt KD, Smith G, Kang SY, Myers S, O'Connor B, Albrecht $M$. Effects of diacerhein in an accelerated canine model of 
osteoarthritis. Osteoarthr Cartil. 1997;5:438-49.

34. Bartels EM, Bliddal H, Schondorff PK, Altman RD, Zhang W, Christensen R. Symptomatic efficacy and safety of diacerein in the treatment of : a meta-analysis of randomized placebocontrolled trials. Osteoarthr Cartil. 2010; 18(3):289-96. doi:10.1016/j.joca.2009.10.006.

35. Pavelka K, Bruyère $\mathrm{O}$, Cooper $\mathrm{C}$, Kanis JA, Leeb BF, Maheu E, et al. Benefits, Risks and Place in the Management of Osteoarthritis. An Opinion-Based Report from the ESCEO. Drugs \& Aging. 2016; 33(2): 75-85.

36. Christiansen BA, Bhatti S, Goudarzi R, Emami S. Management of Osteoarthritis with Avocado / Soybean Unsaponifiables. Curr Med Res Opin 2015; 6(1),30-44

37. Maheu E, Cadet C, Marty M, Moyse D, Kerloch I, Coste P, et al. Randomised, controlled trial of avocado - soybean unsaponifiable ( Piascledine ) effect on structure modi fi cation in hip osteoarthritis?: the ERADIAS study. Ann Rheum Dis. 2014;73(2):376-84.

38. Hitzeman N, Athale N. Opioids for osteoarthritis of the knee or Hip. Am Fam Physician. 2010;81(9):1094-6.

39. Williamson OD, Schroer M, Ruff DD, Ahl J, Margherita A, Sagman D, et al. Onset of response with duloxetine treatment in patients with osteoarthritis knee pain and chronic low back pain: A post hoc analysis of placebo-controlled trials. Clin Ther. 2014;36(4):544-51.

40. Wang ZY, Shi SY, Li SJ, Chen F, Chen H, Lin HZ, et al. Efficacy and Safety of Duloxetine on Osteoarthritis Knee Pain: A Meta-Analysis of Randomized Controlled Trials. Pain Med. 2015;16(7):1373-85.

41. Hochberg MC, Altman RD, April KT, Benkhalti M, Guyatt $\mathrm{G}$, McGowan J et al. American College of Rheumatology 2012 recommendations for the use of nonpharmacologic and pharmacologic therapies in osteoarthritis of the hand, hip, and knee.Arthritis Care Res. 2012;64(4):465-74

42. Meng Z, Huang R. Topical treatment of degenerative knee osteoarthritis. Am J Med Sci. 2017; 355(1): 6-12.

43. Altman RD, Barthel HR. Topical Therapies for Osteoarthritis. Drugs. 2011;71(10):1259-79.

44. Guedes V, Paulo J, Brito I. Topical capsaicin for pain in osteoarthritis: A literature review. Reumatol Clínica. 2018;14(1):40-45.

45. Hameed F, Ihm J. Injectable medications for osteoarthritis. PMRJ. 2012;4 (Suppl 5):S75-81.

46. Jüni P, Hari R, Aws R, Fischer R, Mg S, Reichenbach S, et al. Intra-articular corticosteroid for knee osteoarthritis (review) summary of findings for the main comparison. Cochrane Database Syst Rev. 2015;(10):2-3.

47. Cheng OT, Souzdalnitski D, Vrooman B, et al. Evidencebased knee injections for the management of arthritis. Pain Med. 2012;13(6):740-53.
48. Cole BJ, Verma NN. Is Local Viscosupplementation Injection Clinically Superior to Other Therapies in the Treatment of Osteoarthritis of the Knee?: A Systematic Review of Overlapping Meta-analyses. Arthrosc J Arthrosc Relat Surg. 2015;31(10):2036-2045.

49. Traucy-Uy RL, Lynch SA. Diagnosis and Treatment of Osteoarthritis. Prim Care Clin Off Pract . 2013; 40(4):821836.

50. Smith C, Patel R, Vannabouathong C, Sales B, Rabinovich A, Mccormack R, et al. Combined intra-articular injection of corticosteroid and hyaluronic acid reduces pain compared to hyaluronic acid alone in the treatment of knee osteoarthritis. Knee Surg Sport Traumatol Arthrosc. 2018; doi: 10.1007/s00167-018-5071-7.

51. Dai WL, Zhuo AG, Zhang H, Zhang J. Efficacy of PlateletRich Plasma in the Treatment of Knee Osteoarthritis: A Metaanalysis of Randomized Controlled Trials. Artho. 2016; 33(3)659-70.

52. Di Y, Han C, Zhao L, Ren Y. Is local platelet-rich plasma injection clinically superior to hyaluronic acid for treatment of knee osteoarthritis?? A systematic review of randomized controlled trials. Arthritis Res Ther. 2018;20(1): 128.

53. Vannabouathong C. Nonoperative Treatments for Knee Osteoarthritis: An Evaluation of Treatment Characteristics and the Intra-Articular Placebo Effect. JBJS Rev. 2018;6(7):e5.

54. Therkleson $\mathrm{T}$. Topical ginger treatment with a compress or patch for osteoarthritis symptoms. J Holist Nurs. 2014;32(3)173-82.

55. Bartels EM, Folmer VN, Bliddal H, Altman RD, Juhl C, Tarp $\mathrm{S}$, et al. Efficacy and safety of ginger in osteoarthritis patients: A meta-analysis of randomized placebo-controlled trials. Osteoarthr Cartil .2015;23(1):13-21

56. Lubis AMT, Siagian C, Wonggokusuma E, Marsetio AF. Comparison of Glucosamine-Chondroitin Sulfate with and without Methylsulfonylmethane in Grade I-II Knee Osteoarthritis?: A Double Blind Randomized Controlled Trial. Acta Med Indones. 2017;49(2):105-11.

57. Chevalier X, Eymard F, Richette P. Biologic agents in osteoarthritis: hopes and disappointments. Nat Rev Rheumatol. 2013;9(7):400-10.

58. Yang KG, Raijmakers NJ, van Arkel ER, Caron JJ, Rijk PC, Willems WJ, et al. Autologous interleukin-1 receptor antagonist improves function and symptoms in osteoarthritis when compared to placebo in a prospective randomized controlled trial. Osteoarth Cartil. 2008;16(4):498-505.

59. Smelter E, Hochberg MC. New treatments for osteoarthritis. Curr Opin Rheumatol. 2013;25(3):310-6.

60. Bruyere O, Reginster JY, Bellamy N, Chapurlat R, Richette $\mathrm{P}$, Cooper C. Clinically meaningful effect of strontium ranelate on symptoms in knee osteoarthritis: a responder analysis. Rheum (Oxford). 2014;53(8):1457-64. 